\title{
Institutions and economic development: a Granger causality analysis of panel data evidence
}

\begin{abstract}
This study examines the causal relationship between institutions and economic development using a panel Granger causality test. The study incorporates two institutional datasets, the International Country Risk Guide (ICRG) and World Governance Indicators (WGI). The empirical results based on 60 countries show that there is a bi-directional causality between institutions and economic development. The findings also suggest that causality patterns between institutions and economic performance vary at different stages of income level. Better institutional quality fosters economic development in higher income countries, whereas economic development tends to enhance institutional quality in lower income countries.
\end{abstract}

Item Type: Article

Keyword: Economic performance; Institutions; Governance; Panel Granger causality test 